\title{
Fitness costs of Cry1F resistance in laboratory-selected European corn borer (Lepidoptera: Crambidae)
}

\author{
E. J. G. Pereira ${ }^{1}$, N. P. Storer ${ }^{2}$ \& B. D. Siegfried ${ }^{1}$ \\ 1 Departamento de Biologia Animal, Universidade Federal de Viçosa, Viçosa, MG, Brazil \\ 2 Dow AgroSciences LLC, Indianapolis, IN, USA
}

\section{Keywords}

Bacillus thuringiensis, Ostrinia nubilalis, intrinsic rate of population increase, resistance management, transgenic maize

\section{Correspondence}

Blair D. Siegfried (corresponding author), 202 Entomology Hall, Department of Entomology, University of Nebraska, Lincoln, NE 685830816, USA. E-mail: bsiegfried1@unl.edu

Received: August 12, 2009; accepted: November 12, 2009.

doi: $10.1111 / j .1439-0418.2009 .01488 . x$

\begin{abstract}
The study of fitness costs associated with resistance to toxins from Bacillus thuringiensis Berliner (Bt) is important for understanding resistance evolution and for evaluating resistance management practices that prevent or mitigate resistance. A strain of European corn borer, Ostrinia nubilalis (Hübner) (Lepidoptera: Crambidae) obtained from field collections throughout the U.S. Corn Belt in 1996, was selected in the laboratory for resistance to CrylF by exposure to the toxin incorporated into artificial diet. The selected strain developed more than 3000 -fold resistance to CrylF after 35 generations of selection and readily consumed CrylF expressing maize tissue. Using this resistant strain, a susceptible strain with similar genetic background and reciprocal crosses between them, we estimated fitness costs and their dominance by measuring fitness components and population parameters determined by fertility life tables. Comparison of life-history traits and population growth rates of genotypes homozygous and heterozygous for resistance relative to susceptible genotypes indicated existence of weak and recessive fitness costs associated with resistance. The significance of these results in relation to current resistance management practices is discussed.
\end{abstract}

\section{Introduction}

The European corn borer, Ostrinia nubilalis (Hübner) (Lepidoptera: Crambidae), is one of the most destructive pests of corn in the United States. It is a cosmopolitan species originally distributed in Europe and from there introduced into North America, where it has now spread to most of southern Canada and the U.S. east of the Rocky Mountains (Hudon et al., 1989; Mason et al., 1996). Transgenic corn plants that express proteins from Bacillus thuringiensis (Bt) have become an integral component of crop management systems to control this pest, and therefore, Bt resistance development in $O$. nubilalis would severely limit the economic and environmental benefits of employing transgenic plants or formulated Bt for pest management (Shelton et al., 2002). Transgenic corn hybrids expressing the CrylAb or CrylF insecticidal proteins from $B$. thuringiensis for control of $O$. nubilalis have been used commercially in the U.S. since 1996 and 2003, respectively. In 2008, after 3 years of the release of stacked Bt corn for both corn rootworm (Diabrotica spp.) and corn borer control, Bt corn was planted on $57 \%$ of U.S. corn acreage, exceeding $65 \%$ in some states such as Iowa and Illinois with even higher levels of adoption in some counties (USDA NASS, 2008).

Because of the importance of sustainable use of $\mathrm{Bt}$ as both microbial insecticides and insecticidal proteins expressed in transgenic crop plants, resistance to $\mathrm{Bt}$ has been a subject of extensive research. Laboratory selection experiments have shown the potential for development of resistance to Bt toxins among insect pest species (reviewed by Ferré and Van Rie, 2002) including O. nubilalis (Huang et al., 1997; Bolin et al., 1999; Chaufaux et al,. 2001; Siqueira et al., 2004). Outside the laboratory, Bt resistance has been documented in populations of Plodia interpunctella 
(McGaughey 1985), Plutella xylostela (Tabashnik et al., 1990), and Tricoplusia ni (Janmaat and Myers, 2003) in response to repeated applications of Bt sprays. More recently, field evolved resistance to Bt crops resulting in control failures has been reported in Brusseola fusca (Fuller) to Cryl Ab-producing corn in South Africa (Van Rensburg 2007) and in Spodoptera frugiperda to CrylF-producing corn in Puerto Rico (Matten et al. 2008). Additionally, Tabashnick et al. (2008) have reported resistance to Cryl Ac-producing cotton in Helicoverpa zea based on analysis of more than a decade of resistance monitoring data, although control failures have yet to be detected.

The current scarcity of Bt resistance in the field may be a result of inherent instability of resistance in the absence of Bt exposure. Newly arisen resistance traits are often assumed to be associated with a fitness cost (Coustau et al., 2000). This assumption arises from the observation that resistance genes are rarely fixed in populations, and the maintenance of genetic polymorphisms is thought to be a result of counterbalanced selection pressures (Coustau et al., 2000). Resistance to $\mathrm{Bt}$ has been reported to decline in the absence of selection in a number of laboratory colonies (reviewed by Ferré and Van Rie, 2002; Gassmann et al., 2009). This decline has been attributed to fitness costs, such as a lower larval growth rate (Liu et al., 1999), survival (Groeters et al., 1994), or fecundity and mating success (Groeters et al., 1993) in resistant individuals in the absence of selection. Nevertheless, estimates of overall intrinsic population growth rates of field-derived resistant $P$. xylostella populations have not been found to differ from those of susceptible populations (Sayyed and Wright, 2001). Additionally, no differences in survival or larval weight were found in a strain of CrylAc-resistance Heliothis virescens in the absence of CrylAc (Gould and Anderson, 1991). Despite the uncertainty of fitness costs associated with resistance, some proposed resistance management strategies are enhanced by their presence (Gould, 1998). It is, therefore, important to document fitness costs in order to develop appropriate resistance management strategies.

We have previously reported that a strain of O. nubilalis obtained from field collections throughout the U.S. Corn Belt in 1996 was selected in the laboratory for resistance to CrylF (Pereira et al., 2008a). The selected strain developed more than 3000-fold resistance to CrylF, readily consumed CrylF expressing maize tissue growing to late instars, and displayed a pattern of the response in reciprocal crosses and backcrosses that was consistent with autosomal, recessive, and simple monogenic inheritance of resistance (Pereira et al., 2008a). The mechanism of resistance in this strain remains uncertain as no evidence of reduced toxin binding to midgut epithelia or enhanced degradation by luminal gut proteases was observed in the resistant larvae (Pereira et al., 2009). Here we report results of a laboratory experiment conducted to determine relative fitness of CrylF-resistant, susceptible and $F_{1}$ progeny of reciprocal crosses between resistant and susceptible European corn borers. Life-history characteristics including pupal weight, development time and growth rate were measured and population growth parameters were calculated for the four groups. Results are discussed in terms of strength and inheritance of fitness costs as well as their implications for resistance management.

\section{Materials and Methods}

\section{Insects}

Four 0 . nubilalis lines were utilized in the fitness comparisons: the CrylF-selected and control strains assumed to be homozygous for resistance and susceptibility, respectively, and the two hybrid $F_{1}$ progeny derived from reciprocal crosses between susceptible and resistant parents (Pereira et al., $2008 \mathrm{~b})$. The selected strain originated from insects collected throughout the central U.S. Corn Belt in 1996 and has been maintained in the laboratory for at least 50 generations (Pereira et al., 2008b). Resistance has been maintained by repeated selection every two-three generations with CrylF applied on the surface of the rearing diet for seven days (60 ng/ $\mathrm{cm}^{2}$, the upper limit of the $\mathrm{LC}_{99}$ for susceptible populations), although insects were not exposed to toxin in the generation immediately prior to experiments. The selected strain exhibited greater than 3000-fold resistance to CrylF based on diet bioassays and readily consumed CrylF expressing maize tissue (Pereira et al., 2008a,b). The population size of selected colony was maintained at ca. 1000 individuals every generation. The susceptible strain was derived from the CrylF selected strain after the first 30 generations of selection before resistance was fixed as described elsewhere (Pereira et al., 2008a,b).

To generate $F_{1}$ larvae, corn borer pupae from susceptible and resistant strains were separated by sex according to the ventral morphology of their caudal end (Heinrich, 1919). One hundred CrylF-selected females were pooled with 100 control males, and 100 control females were pooled with 100 CrylF-selected males in mating cages before adult emergence. The fitness comparisons were initiated with neonates of 
the four lines, which were maintained at $25 \pm 2{ }^{\circ} \mathrm{C}$ and $65 \pm 2 \% \mathrm{RH}$ under a LD 16:8 h cycle and reared on the wheat germ-based diet (Lewis and Lynch, 1969) that is used for standard rearing.

\section{Growth rate}

Thirty-two randomly selected unfed neonates (within $24 \mathrm{~h}$ of eclosion) from the selected and control strains, and $F_{1}$ progeny of reciprocal crosses were weighed. One individual neonate was placed in each independent well of a 32-well bioassay tray containing fresh rearing diet sufficient for complete larval development. Pupation was recorded daily, and individuals were removed, weighed, and placed in a Petri dish containing a moistened filter paper to avoid dehydration. The growth rate (GR) was calculated using the formula (Radford, 1967): GR $=\left[W_{2}\right.$ $\left.(\mathrm{mg})-W_{1}(\mathrm{mg})\right] / T$ where $W_{1}$ and $W_{2}$ are the neonate larval (L1) and pupal weights, respectively, and $T$ is the time (days) from Ll to the pupal stage (Sayyed and Wright, 2001; Raymond et al., 2005).

\section{Fecundity and number of offspring produced}

For each of the two strains and $F_{1}$ progeny of reciprocal crosses, 10 newly-emerged adult males and females from the growth rate study were paired randomly. Each pair was placed in a small mating cage $(6 \times 6 \times 10 \mathrm{~cm})$ made of polyvinylchloride (Siegfried et al., 2001) and provided with cotton wool saturated with adult diet (1.4\% agar, 40\% sucrose in $\mathrm{w} / \mathrm{v}$ ). The egg laying surface of the cages were at a $45^{\circ}$ angle and covered with $0.6-\mathrm{cm}$ screen upon which wax paper sheets were placed and used as oviposition substrate.

Cages were misted with water daily, and the number of egg masses were recorded, weighed, and transferred to a small Petri dish (6 cm diameter) containing a water-saturated filter paper as source of moisture. Most eggs hatched within 5 days, but eggs were allowed up to 7 days to hatch. The daily number of neonates produced per female each day was recorded. Larvae were transferred to rearing pans containing normal rearing diet (Lewis and Lynch, 1969) in order to estimate the neonate-to-adult survivorship and the number of offspring female moths produced by each parental female.

\section{Intrinsic rate of population increase}

Methods were adapted from Alyokhin and Ferro (1999) and Sayyed and Wright (2001). To estimate parameters related to the population growth potential in each $O$. nubilalis line, we assumed that the population has an exponential growth described in the model $N_{t}=N_{0} \times \mathrm{e}^{r m \times t}$, where $N_{t}$ is the size of the population at time $t ; N_{O}$ is the initial size of the population, and $r_{m}$ is a parameter related with the rate of population growth referred to as the intrinsic rate of increase (Birch, 1948). The life-table format (Carey, 1993; Southwood and Henderson, 2000) was used to study numerical differences in the four lines of O. nubilalis. Population growth parameters were determined as described by Birch (1948) and Carey (1993) using a sAs program developed by Maia et al. (2000). The intrinsic rate of increase was obtained by iteration of the Lotka equation (Birch, 1948): $\sum \mathrm{e}^{-r x} l_{x} m_{x}=1$, where $x$ is the pivotal age class, $l_{x}$ is the survivorship at pivotal age $x$, and $m_{x}$ is the number of adult-female offspring produced by all experimental females alive at each pivotal age $x$. The net reproductive rate or rate of multiplication per generation, $R_{0}=\Sigma\left(l_{x} m_{x}\right)$, the mean generation time, $T=\ln \left(R_{0}\right) / r$, and the finite rate of increase or rate of multiplication per day, $\lambda=\ln (r)$ were also calculated.

\section{Statistical analyses}

Pupal weight, development time, and mean growth rate were analysed by a two-way analysis of variance (ANOVA) with $O$. nubilalis genotype and sex as main effects. Residual analysis (PROC MIXED, PROC UNIVARATE) was employed to ensure that the assumptions of homogeneity of variance and normality were met before data were analysed. The means were separated at the $\alpha$ level of 0.05 using Fisher's protected least square difference (PROC MIXED) (SAS Institute, 2002).

Variances associated with the population growth parameters were estimated by the jackknife method (Efron, 1982; Meyers et al., 1986) using the sAs program developed by Maia et al. (2000). The program allows the calculation of confidence intervals for all estimated parameters and provides one-sided and two-sided $t$-tests to perform pairwise or multiple comparison between groups using their respective $\mathrm{P}$ values.

\section{Results}

\section{Larval development}

Significant differences $(\mathrm{P}<0.05)$ existed between the sexes for both pupal weight and growth rate but not for development time (Table 1). These life-history 
Table 1 F-test values and probabilities for the two-factor analysis of variance on life-history traits of four European corn borer genotypes reared in artificial diet

\begin{tabular}{|c|c|c|c|c|c|c|c|}
\hline \multirow[b]{2}{*}{ Source } & \multirow[b]{2}{*}{ df } & \multicolumn{2}{|c|}{ Pupal weight } & \multicolumn{2}{|c|}{$\begin{array}{l}\text { Development } \\
\text { time }\end{array}$} & \multicolumn{2}{|c|}{ Growth rate ${ }^{1}$} \\
\hline & & $F$ & $P$ & $F$ & $F$ & $P$ & $P$ \\
\hline ECB genotype & 3 & 7.31 & 0.0002 & 41.39 & $<0.0001$ & 23.95 & $<0.0001$ \\
\hline Sex & 1 & 364.17 & $<0.0001$ & 1.14 & 0.2882 & 249.16 & $<0.0001$ \\
\hline $\mathrm{ECB} \times \operatorname{sex}$ & 3 & 1.14 & 0.3365 & 3.63 & 0.0149 & 3.35 & 0.0215 \\
\hline Error & 119 & & & & & & \\
\hline
\end{tabular}

Measurements were obtained from 30 to 32 individuals.

${ }^{1}$ Growth rate $=$ (final mass - initial mass) $/$ no. of days (see Materials and methods).

characteristics varied among the $O$. nubilalis genotypes, and the interaction $O$. nubilalis genotype $\times$ sex was also significant (Table 1).

Pupal weight, development time, and growth rates of the selected and control strains and $F_{1}$ progeny of reciprocal crosses are shown in Fig. la-c. Pupal weight was similar for males of all four genotypes. In contrast, female pupal weights of the CrylFselected strain, and progeny of reciprocal crosses (i.e.
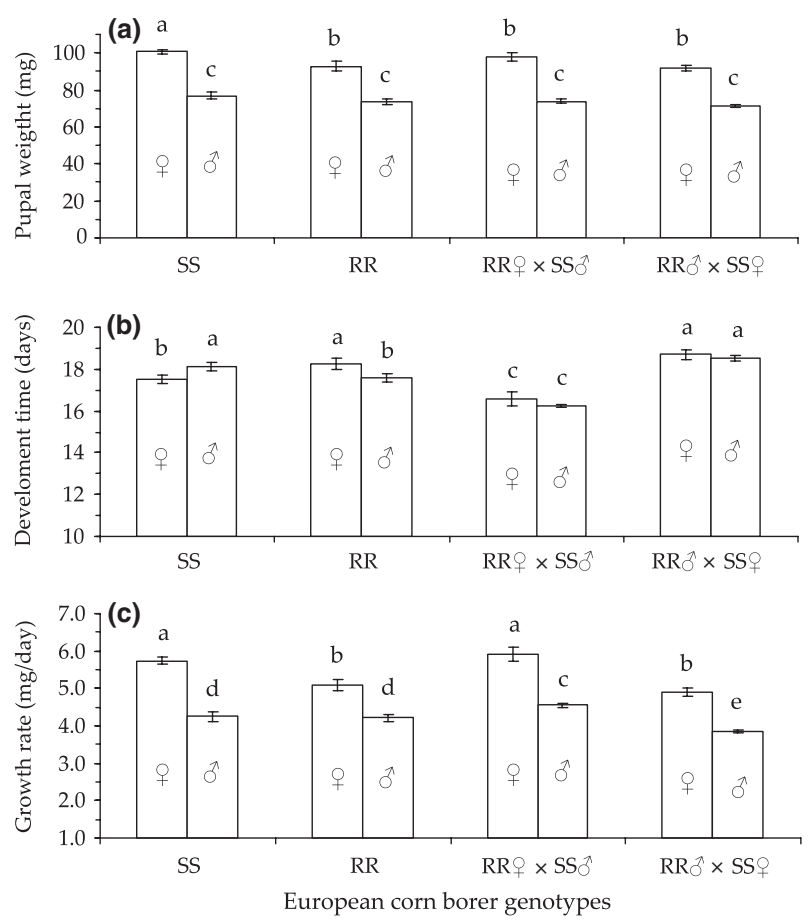

Fig. 1 Comparison of larval, life-history traits among European corn borer genotypes. (a) Pupal weight, (b) development time, and (c) mean relative growth weight. Error bars represent standard errors. Bars in a chart followed by the same letter are not significantly different (Fisher's protected LSD test, $\mathrm{P}>0.05)$. resistant homozygotes and heterozygotes, respectively) were significantly lower than that of the control strain (i.e. susceptible heterozygotes). The development time varied between the sexes for homozygous larvae; susceptible females (SS) developed faster than did resistant females (RR), while the opposite occurred with the males. However, the magnitude of the difference was less than a day for both sexes. The progeny of CrylF-Sel. $q \times$ Control $\hat{\sigma}$ (i.e. $\mathrm{RR}_{+} \times \mathrm{SS}_{\hat{O}}$ ) had the shortest development time and pupated approximately two days earlier than the other genotypes. Resistant homozygous females accumulated less biomass (i.e. displayed lower growth rates) than did susceptible homozygous females (about $1 \mathrm{mg}$ per day); this same trend was observed in the progeny of $\mathrm{RR}_{+} \times \mathrm{SS}_{\hat{\sigma}}$. No clear reduction in the larval growth rates of males was associated with resistance.

\section{Fecundity}

Analysis of variance indicated only marginally significant differences among the genotypes in the number of egg masses $\left(F_{3,36}=2.38 ; \mathrm{P}=0.0858\right)$, egg mass weight $\left(F_{3,36}=2.78 ; \mathrm{P}=0.0551\right)$, and number neonates produced $\left(F_{3,36}=2.57 ; \mathrm{P}=0.0690\right)$. Fecundity parameters of CrylF-selected moths tended to be lower than those of the control and $F_{1}$ moths (Fig. 2), especially the number egg masses (Fig. 2a) and neonates produced (Fig. 2c). Resistant homozygous moths produced $45 \%$ fewer offspring than control females (i.e. susceptible homozygotes) and approximately $65 \%$ fewer than progeny of reciprocal crosses (i.e. heterozygotes). Heterozygous moths tended to produce heavier egg masses and more offspring than the other genotypes (Fig. 2).

\section{Population growth}

Table 2 summarizes the parameters of potential population growth for the four $O$. nubilalis genotypes reared in laboratory conditions. The same trend observed for traits related to fecundity was observed for the population growth parameters of the four the genotypes. Overall, the intrinsic rate of population increase $\left(r_{m}\right)$ tended to be lower for resistant homozygotes and higher for heterozygotes relative to susceptible homozygotes.

\section{Discussion}

The results of the present study indicate that there is a weak fitness cost associated with CrylF resistance 

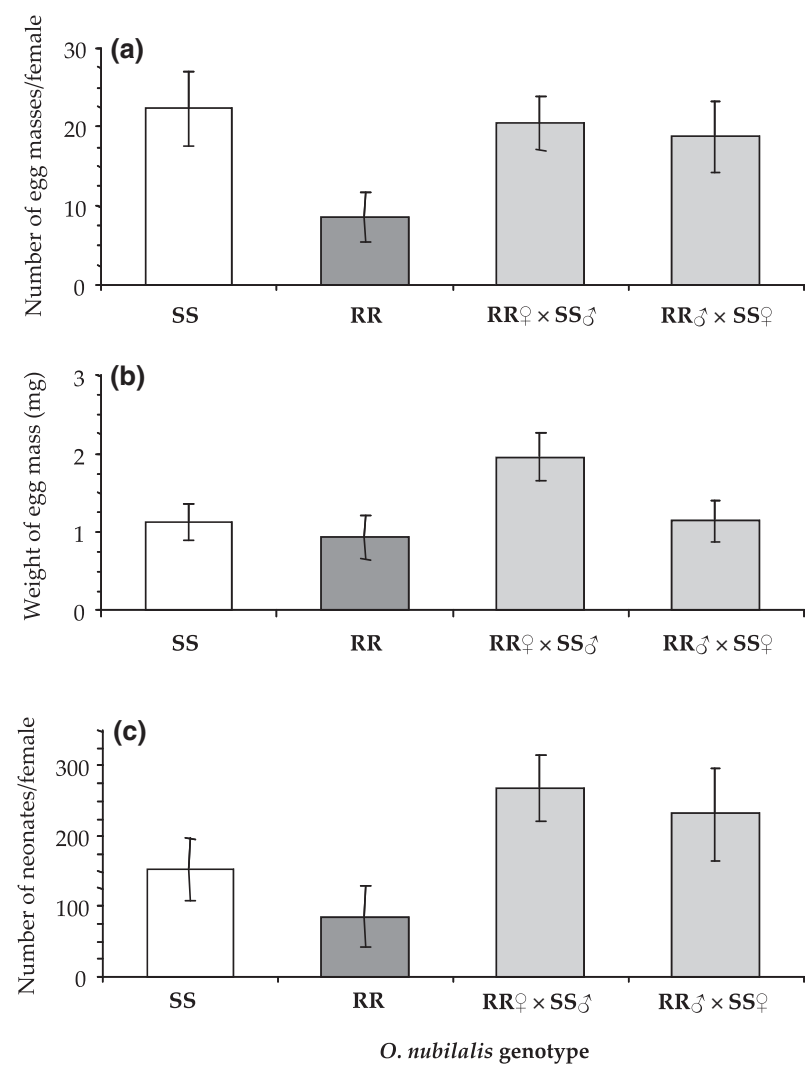

Fig. 2 Comparison of fecundity parameters among O. nubilalis genotypes. (a) Number of egg masses laid by each female, (b) individual weight of egg masses, and (c) number of neonates produced by each female. Error bars represent standard errors $(n=10)$. No significant differences (ANOVA, P > 0.05) were detected for any of the fecundity parameters.

in the European corn borer. Importantly, heterozygous individuals were equally fit or fitter than the susceptible homozygotes indicating that the slight fitness costs appear to be recessive. This result could have important practical implications to resistance management because when heterozygotes have equivalent fitness to susceptible homozygotes, resistant alleles are expected to persist in at least some populations (Roush and McKenzie, 1987). Therefore, it is critical to estimate the frequency of CrylF-resistance alleles (Gould, 1998) in field populations of $O$. nubilalis to effectively monitor resistance evolution. Elucidation of the resistance mechanism (Pereira et al., 2009) will be an important step towards identification of a resistance-associated mutation and development of molecular markers that are amenable to high throughput screening and may provide increased precision and sensitivity to monitoring efforts. In addition, as pointed out by Coustau et al. (2000), fitness costs are more thoroughly understood when the mutations that confer resistance have been identified allowing a better understanding of physiological consequences of resistance.

It should be noted that our estimates of relative fitness were obtained under a single set of environmental conditions designed to optimize $O$. nubilalis rearing. Resistance-associated fitness costs might have been more apparent under normal field conditions or in an unfavorable environment (Janmaat and Myers, 2005; Raymond et al., 2005). Therefore, in future studies it will be important to compare relative fitness of $O$. nubilalis genotypes under different ecological conditions so that the genotype-environment interaction can be estimated thus increasing the chance of detection of costs of resistance (Fry, 1993). In planta comparisons of fitness may provide a better approximation of the environment that insects face in the field. Corn hybrids with different concentrations of defensive phytochemicals such as dimboa could also magnify costs (Carrière et al., 2004) and should be tested. Additionally, it may be relevant to estimate the ability of the resistant genotype to overwinter by measuring the ability to enter and break diapause under simulated conditions in the laboratory (Alyokhin and Ferro, 1999).

Table 2 Comparison of population growth parameters (mean \pm SE) for 0 . nubilalis genotypes reared in artificial diet $(n=10)$

\begin{tabular}{|c|c|c|c|c|c|}
\hline \multirow[b]{2}{*}{ Genotype or generation } & \multicolumn{5}{|c|}{ Population growth parameter } \\
\hline & $R_{0}$ & $r_{m}$ & $T$ & $D T$ & $\lambda$ \\
\hline SS (Control) & $50.7 \pm 14.69$ & $0.132 \pm 0.010$ & $30.08 \pm 0.64$ & $5.22 \pm 0.44$ & $1.141 \pm 0.012$ \\
\hline RR (Cry1F-Selected) & $34.3 \pm 17.82$ & $0.126 \pm 0.019$ & $29.42 \pm 0.69$ & $5.34 \pm 0.98$ & $1.134 \pm 0.021$ \\
\hline $\mathrm{F}_{1}(\mathrm{RR}+\times \mathrm{SS} \widehat{)})$ & $72.0 \pm 12.56$ & $0.151 \pm 0.006$ & $28.44 \pm 0.28$ & $4.58 \pm 0.19$ & $1.163 \pm 0.007$ \\
\hline $\mathrm{F}_{1}\left(\mathrm{RR}_{0} \hat{\mathrm{C}} \times \mathrm{SS}\right.$ ㅇ & $78.4 \pm 21.91$ & $0.143 \pm 0.010$ & $30.79 \pm 0.52$ & $4.83 \pm 0.34$ & $1.154 \pm 0.011$ \\
\hline
\end{tabular}

No significant differences $(P>0.05)$ by the jackknife method using the SAS program developed by Maia (2000) were detected for any of the population growth parameters.

$R_{0}$, net reproductive rate (females/female/generation); $r_{m}$, intrinsic rate of population increase (per day); $T$, Mean length of a generation (days); $D T$, time for the population double its size (days); $\lambda$, finite rate of population increase (per day) (see Materials and methods). 
In the laboratory, fitness costs of $\mathrm{Bt}$ resistance have been observed with some resistant strains of Plodia interpunctella (Oppert et al., 2000), Pectinophora gossypiella (Carrière et al., 2001), Plutella xylostella (Groeters et al., 1994), Leptinotarsa decemlineata (Alyokhin and Ferro, 1999), Trichoplusia ni (Janmaat and Myers, 2003), and Helicoverpa armigera (Akhurst et al., 2003), whereas other strains have not displayed such costs (Tang et al., 1997; Ramachandran et al., 1998; Sayyed and Wright, 2001). These observations indicate that fitness costs were not always detected under laboratory conditions. It is unclear whether different rearing conditions between laboratories can, in part, explain this variation (Cerda et al., 2003), or if resistance costs to Bt toxins may be cryptic and only evidenced upon instability of resistance (Sayyed and Wright, 2001; Gassmann et al., 2009).

The present study represents a first step towards documentation of fitness costs associated with CrylF resistance in populations of this species and is one of the few studies that estimate the inheritance of fitness costs and the intrinsic rate of population increase, a direct index of fitness. Although both the susceptible and susceptible strains were derived from a common genetic background, subsequent rearing in isolation for multiple generations could have resulted in significant genetic divergence. It cannot be ruled out that such strain differences contributed to the slight effects observed on some fitness parameters and could have confounded estimates of fitness dominance due to heterosis of hybrid vigour (Gassmann et al., 2009). More refined studies in the laboratory, greenhouse, or in the field are needed to measure the relative fitness of the resistant strain and $F_{1}$ progeny in competition with a susceptible population sharing similar genetic background. Additionally, documentation of fitness costs influencing behaviours associated with mating (Groeters et al., 1993) may provide valuable insight into trade-offs between resistance and fitness. The combination of several analytical approaches should provide the most robust estimates of the relative fitness of individuals carrying resistant allele(s).

\section{Acknowledgements}

We thank Terence Spencer for assisting with surface selection, insect rearing, and bioassays. Funding for this research was provided by Dow AgroSciences LLC. A fellowship for E. Pereira was provided by the Brazilian Ministry of Education through the CAPES Foundation.

\section{References}

Akhurst RJ, James W, Bird LJ, Beard C, 2003. Resistance to the CrylAc delta-endotoxin of Bacillus thuringiensis in the cotton bollworm, Helicoverpa armigera (Lepidoptera: Noctuidae). J. Econ. Entomol. 96, 1290-1299.

Alyokhin AV, Ferro DN, 1999. Relative fitness of Colorado potato beetle (Coleoptera: Chrysomelidae) resistant and susceptible to the Bacillus thuringiensis Cry3A toxin. J. Econ. Entomol. 92, 510-515.

Birch LC, 1948. The intrinsic rate of natural increase of an insect population. J. Anim. Ecol. 17, 15-26.

Bolin PC, Hutchison WD, Andow DA, 1999. Long-term selection for resistance to Bacillus thuringiensis Cryl Ac endotoxin in a Minnesota population of European corn borer (Lepidoptera: Crambidae). J. Econ. Entomol. 92, 1021-1030.

Carey JR, 1993. Applied demography for biologists with special emphasis on insects. Oxford University Press, Oxford.

Carrière Y, Ellers-Kirk C, Biggs R, Higginson DM, Dennehy TJ, Tabashnik BE, 2004. Effects of gossypol on fitness costs associated with resistance to Bt cotton in pink bollworm. J. Econ. Entomol. 97, 1710-1718.

Carrière Y, Ellers-Kirk C, Liu YB, Sims MA, Patin AL, Dennehy TJ, Tabashnik BE, 2001. Fitness costs and maternal effects associated with resistance to transgenic cotton in the pink bollworm (Lepidoptera : Gelechiidae). J. Econ. Entomol. 94, 1571-1576.

Cerda H, Sayyed AH, Wright DJ, 2003. Laboratory culture conditions affect stability of resistance to Bacillus thuringiensis CrylAc in Plutella xylostella (Lep., Plutellidae). J. Appl. Entomol. 127, 142-145.

Chaufaux J, Seguin M, Swanson JJ, Bourguet D, Siegfried BD, 2001. Chronic exposure of the European corn borer (Lepidoptera: Crambidae) to CrylAb Bacillus thuringiensis toxin. J. Econ. Entomol. 94, 1564-1570.

Coustau C, Chevillon C, ffrench-Constant R, 2000. Resistance to xenobiotics and parasites: can we count the cost? Trends Ecol. Evol. 15, 378-383.

Efron B, 1982. The jackknife, the bootstrap, and other resampling plans. Society for Industrial and Applied Mathematics, Philadelphia.

Ferré J, Van Rie J, 2002. Biochemistry and genetics of insect resistance to Bacillus thuringiensis. Annu. Rev. Entomol. 47, 501-533.

Fry JD, 1993. The "general vigor" problem: can antagonistic pleiotropy be detected when genetic covariances are positive? Evolution 47, 327-333.

Gassmann AJ, Carrière Y, Tabashnik BE, 2009. Fitness costs of insect resistance to Bacillus thuringiensis. Annu. Rev. Entomol. 54, 147-163.

Gould F, 1998. Sustainability of transgenic insecticidal cultivars: integrating pest genetics and ecology. Annu. Rev. Entomol. 43, 701-726. 
Gould F, Anderson A, 1991. Effects of Bacillus thuringiensis and HD-73 delta-endotoxin on growth, behavior, and fitness of susceptible and toxin-adapted strains of Heliothis virescens (Lepidoptera, Noctuidae). Environ. Entomol. 20, 30-38.

Groeters FR, Tabashnik BE, Finson N, Johnson MW, 1993. Resistance to Bacillus thuringiensis affects mating success of the diamondback moth (Lepidoptera, Plutellidae). J. Econ. Entomol. 86, 1035-1039.

Groeters FR, Tabashnik BE, Finson N, Johnson MW, 1994. Fitness costs of resistance to Bacillus thuringiensis in the diamondback moth (Plutella xylostella). Evolution 48, 197-201.

Heinrich C, 1919. Note on the European corn borer (Pyrausta nubilalis Hübner) and its nearest American allies, with description of larvae, pupae and one new species. J. Agric. Res. 18, 171-184.

Huang FN, Higgins RA, Buschman LL, 1997. Baseline susceptibility and changes in susceptibility to Bacillus thuringiensis subsp. kurstaki under selection pressure in European corn borer (Lepidoptera: Pyralidae). J. Econ. Entomol. 90, 1137-1143.

Hudon M, LeRoux EJ, Harcourt DG, 1989. Seventy years of European corn borer (Ostrinia nubilalis) research in North America. Agric. Zool. Rev. 3, 53-96.

Janmaat AF, Myers J, 2003. Rapid evolution and the cost of resistance to Bacillus thuringiensis in greenhouse populations of cabbage loopers, Trichoplusia ni. Proc. R. Soc. Lond. B 270, 2263-2270.

Janmaat AF, Myers JH, 2005. The cost of resistance to Bacillus thuringiensis varies with the host plant of Trichoplusia ni. Proc. R. Soc. Lond. B 272, 1031-1038.

Lewis LC, Lynch RE, 1969. Rearing the European corn borer, Ostrinia nubilalis (Hübner), on diets containing corn leaf and wheat germ. Iowa J. Sci. 44, 9-14.

Liu YB, Tabashnik BE, Dennehy TJ, Patin AL, Bartlett AC, 1999. Development time and resistance to $\mathrm{Bt}$ crops. Nature 400, 519-519.

Maia ADN, Luiz AJB, Campanhola C, 2000. Statistical inference on associated fertility life table parameters using jackknife technique: computational aspects. J. Econ. Entomol. 93, 511-518.

Mason CE, Rice ME, Calvin DD, Van Duyn JW, Showers WB, Hutchison WD, Witkowski JF, Higgins RA, Onstad DW, Dively GP, 1996. European corn borer - ecology and management. Iowa State University, Ames, IA.

Matten SR, Head GP, Quemada HD, 2008. How governmental regulation can help or hinder the integration of Bt crops into IPM programs. In: Integration of insectresistant genetically modified crops within IPM programs. Ed. by Romeis J, Shelton AM, Kennedy GG, Springer, New York, 27-39.

McGaughey WH, 1985. Insect resistance to the biological insecticide Bacillus thuringiensis. Science 229, 193-195.
Meyers JS, Ingersoll CG, McDonald LL, Boyce MS, 1986. Estimating uncertainty in population growth rates: jackknife vs. bootstrap techniques. Ecology 67, 1156-1 166.

Oppert B, Hammel R, Throne JE, Kramer KJ, 2000. Fitness costs of resistance to Bacillus thuringiensis in the Indianmeal moth, Plodia interpunctella. Entomol. Exp. Appl. 96, 281-287.

Pereira EJG, Lang BA, Storer NP, Siegfried BD, 2008a. Selection for CrylF resistance in the European corn borer and cross-resistance to other Cry toxins. Entomol. Exp. Appl. 126, 115-121.

Pereira EJG, Storer NP, Siegfried BD, 2008b. Inheritance of CrylF resistance in laboratory-selected European corn borer and its survival on transgenic corn expressing the CrylF toxin. Bull. Entomol. Res. 98, 621-629.

Pereira EJG, Siqueira HAA, Zhuang M, Storer NP, Siegfried BD, 2009. Measurements of CrylF binding and activity of luminal gut proteases in susceptible and CrylF resistant Ostrinia nubilalis larvae (Lepidoptera: Crambidae). J. Invertebr. Pathol. 101, doi: 10.1016/j. jip.2009.08.014.

Radford PJ, 1967. Growth analysis formulae - their use and abuse. Crop Sci. 7, 171-175.

Ramachandran S, Buntin GD, All JN, Tabashnik BE, Raymer PL, Adang MJ, Pulliam DA, Stewart CN, 1998. Survival, development, and oviposition of resistant diamondback moth (Lepidoptera : Plutellidae) on transgenic canola producing a Bacillus thuringiensis toxin. J. Econ. Entomol. 91, 1239-1244.

Raymond B, Sayyed AH, Wright DJ, 2005. Genes and environment interact to determine the fitness costs of resistance to Bacillus thuringiensis. Proc. R. Soc. Lond. B 272, 1519-1524.

Roush RT, McKenzie JA, 1987. Ecological genetics of insecticide and acaricide resistance. Annu. Rev. Entomol. 32, 361-380.

SAS Institute, 2002. SAS user's manual, version 9.1. SAS Institute, Cary, NC.

Sayyed AH, Wright DJ, 2001. Fitness costs and stability of resistance to Bacillus thuringiensis in a field population of the diamondback moth Plutella xylostella L. Ecol. Entomol. 26, 502-508.

Shelton AM, Zhao JZ, Roush RT, 2002. Economic, ecological, food safety, and social consequences of the deployment of Bt transgenic plants. Annu. Rev. Entomol. 47, 845-881.

Siegfried BD, Zoerb AC, Spencer T, 2001. Development of European corn borer larvae on Event 176 Bt corn: influence on survival and fitness. Entomol. Exp. Appl. 100, 15-20.

Siqueira HAA, Moellenbeck D, Spencer T, Siegfried BD, 2004. Cross-resistance of CrylAb-selected Ostrinia nubilalis (Lepidoptera: Crambidae) to Bacillus thuringiensis delta-endotoxins. J. Econ. Entomol. 97, 1049-1057. 
Southwood TRE, Henderson PA, 2000. Ecological methods, 3rd edn. Blackwell Science, London.

Tabashnik BE, Cushing NL, Finson N, Johnson MW, 1990. Field development of resistance to Bacillus thuringiensis in diamondback moth (Lepidoptera, Plutellidae). J. Econ. Entomol. 83, 1671-1676.

Tang JD, Gilboa S, Roush RT, Shelton AM, 1997. Inheritance, stability, and lack-of-fitness costs of fieldselected resistance to Bacillus thuringiensis in diamond- back moth (Lepidoptera: Plutellidae) from Florida. J. Econ. Entomol. 90, 732-741.

U.S. Department of Agriculture National Agricultural Statistics Service, 2008. Acreage 2008 Report (http:// usda.mannlib.cornell.edu/usda/current/Acre/Acre-0630-2008.pdf). USDA NASS, Washington.

Van Rensburg JBJ, 2007. First report of field resistance by stem borer, Busseola fusca (Fuller) to Bt -transgenic maize. S. Afr. J. Plant Soil 24, 147-151. 